\title{
Carpool Karaoke: deconstructing the directly lived experience of hearing oneself singing
}

\section{George Rossolatos}

To cite this article: George Rossolatos (2016): Carpool Karaoke: deconstructing the directly lived experience of hearing oneself singing, Social Semiotics, DOI: 10.1080/10350330.2016.1261480

To link to this article: http://dx.doi.org/10.1080/10350330.2016.1261480

册 Published online: 24 Nov 2016.

Submit your article to this journal $\pi$

Q View related articles $₫$

View Crossmark data ־ 


\title{
Carpool Karaoke: deconstructing the directly lived experience of hearing oneself singing
}

\author{
George Rossolatos
}

Department of English, University of Kassel, Kassel, Germany

\begin{abstract}
The various ways whereby spatial conditions afford to monumentalize culture and to appropriate geographically demarcated places in terms of individual and collective meaning structures has been amply documented in urban cultural studies. However, considerably less attention has been paid to how cultural identity is produced against the background of musical temporality. By way of a phenomenological inquiry into the staged spectacle of James Corden's (the host of CBS Network's Late Late Show) Carpool Karaoke, this paper addresses the issues of directly lived experience and authenticity as facets of cultural identity. By critically discussing the assumptions of self-presence and auto-affectivity while singing and listening to one's sung voice against the background of pre-recorded songs, the notion of directly lived musical experience is put to the test. Furthermore, by examining the dramaturgical scaffolding of Carpool Karaoke, the analysis points to wider implications for post-modern cultural studies in terms of an identified ironic reversal of modernist universal criteria of legitimacy in favor of a celebration of postmodern being-with inauthentically. The analysis of the selected Carpool Karaoke corpus utilizes a resourceful blend of phenomenological method, semiotics and interpretive videography while challenging embedded orthodoxies in the extant literature.
\end{abstract}

\section{KEYWORDS}

Spectacles' consumption; phenomenology; semiotics; interpretive videography; cultural identity; urban studies; talk-show

\section{Introduction: music as a pre-condition for the Carpool Karaoke lived experience}

The impact of music on individual and collective cultural identity is paramount. Music unifies the audience on the syntagmatic level of social activity (Van Leeuwen 1991). The multifarious ways whereby music is consumed as leisure artifact, the increasing occasions of consumption thanks to technological advancements and its essential role as vehicle for animating urban existence have been amply documented. In the context of modern cities, as "geographical plexus, economic organizations, institutional processes, aesthetic symbols of collective unity" (Mumford 2004, 29) music affords to blur the dividing lines between the public and private spheres (Sheller and Urry 2004), while redefining "objective" time in favor of its constant renegotiation in memory. Living in a modern urban 
environment is inextricably linked with consuming music, not simply as a leisure activity, but as an integral aspect of urban existence.

Listening to music while driving one's car, alone or with others, constitutes a main use occasion of this cultural artifact. "Automobility is a complex amalgam of interlocking machines, social practices and ways of dwelling" (Sheller and Urry 2004). However, the function of music in the dramaturgical armory of James Corden, host of CBS's Late Late Show, is not as clear-cut. Corden employs the Carpool Karaoke as a "reality TV" component of his show. This "reality" dimension may be appreciated by reading the Carpool Karaoke as a directly lived experience that takes place outside of the cultural space where the main show is enacted, as against the main show that deploys within the mediatized space of a talk-show. Furthermore, Corden's driving around the city while singing to "radio" transmitted tacks along with his co-passengers in a karaoke-style, participatory mode (Man Kong Lum 2005) assumes a conditional role with regard to the rest components that make up this occasion of cultural production and entertainment. As DeNora (2006) contends, listening to music is not simply part of the features that make up a cultural predicament, alongside actors, space, mode of interaction, the surrounding signs and their materiality, but an essential condition of their being experienced as a meaningful gestalt.

The direct immersion in lived experiences afforded by the musical mode is evinced in this spectacle as a structure of singing alongside others in the participatory mode of the karaoke-style. The authenticity of the experience is safeguarded by the adoption of a reality TV orientation (in opposition to the dramaturgical scaffolding of the main show). Authenticity has been repeatedly argued as being a main trait of reality TV (Hill 2005), especially for the viewers of "reality" oriented spectacles, albeit not entirely incontestably so.

This study critically addresses the directly lived experiential character of being present to oneself while listening to one's sung voice and the "authenticity" of the Karaoke spectacle, by pursuing the following interpretive path: initially, a descriptive account of the spectacle's stage-setting is offered in order to anchor as concretely as possible the ensuing phenomenological discussion in the involved semiotic resources. Then, a phenomenologically oriented discussion deploys against the background of key concepts, such as self-presence, voice, auto-affectivity, that allow us to understand the unique ways whereby cultural identity (Brown and Sellen 2006) is formed in Corden's Karaoke on-the-go. The phenomenological exposition of "directly lived experience" is then deconstructed by recourse to Derridean argumentation pertaining to vococentrism and the metaphysics of presence. The following section resumes the analysis of Corden's stagesetting orientation, viewed as a post-modern spectacle that is permeated by ironic selfreversal. Finally, the concluding section wraps up why Corden's Karaoke constitutes a novel form of cultural production, while highlighting the shift from universalist criteria of legitimacy as grounded in transcendental consciousness towards mediators of cultural production.

\section{The methodological framework of this study}

From a methodological point of view, this study adopts a resourceful blend of social and music semiotics (Monelle 1992; Tarasti 1997; Van Leeuwen 1999; Machin 2010), interpretive videography (Pink 2006; Knoblauch 2012) as a focused extension of ethnographic methods in popular music research (Cohen 1993) within an encompassing interpretive 
ethnographic framework (Denzin 1997), and phenomenological method (Husserl 1980; Schutz 1996; Lindseth and Norberg 2004).

It draws on Husserl's (1980) transcendental phenomenology, Schutz's (1996) social phenomenology with an added focus on the phenomenology of music as lived experience, Derrida's (1973) deconstructionist criticisms against the former, and Heidegger's (1972, 1985, 2001) phenomenological ontology (to a lesser extent). This phenomenological cohort affords to cast a detailed eye on how lived experiences are constituted, a term that more often than not appears to be intuitively resonant without any further interpretation, as rightly noted by Denzin $(1997,54)$. The import of phenomenology in the adopted cultural analytic allows us to obtain a nuanced understanding of the semiotic resources that make up the stage-setting of the karaoke spectacle insofar as issues of self-presence and listening to one's voice constitute integral aspects of phenomenological theory and method, such as "bracketing".

The phenomenological method leans quite heavily on semiotic or, at least, sign-related terminology, and hence is not at all dissonant with a social semiotic perspective. Despite the fact that phenomenological concepts have been cross-fertilized with semiotic ones, culminating in hybrid conceptual frameworks and interpretive methods of analysis (cf. Lanigan 1984, 1997; Tarasti 1987; Sobchack 1992), the scope of such inter-disciplinary transfers has been rather limited.

Although Husserlian phenomenology contains an inter-subjective prong, admittedly this was not its strong part (cf. Rossolatos 2015a for a criticism of Husserl's passive synthesis in this respect). Rather, it turned out to be its Achilles' heel which subsequent generations of social phenomenologists (e.g. Schutz), but also Heidegger, who was Husserl's contemporary and student, attempted to alleviate. Yet, phenomenology, an inherently pluralist theoretical movement, still constitutes a dominant perspective across various social sciences and humanities, such as philosophy, psychoanalysis, sociology (from social phenomenology [Vaitkus 1990] to ethnomethodology to phenomenological sociology; Ferguson 2006), film (Shaw 2000), literary (by way of deconstruction) and cultural studies (cf. Friesen and Irwin 2014; Bondi and La Mantia 2015; Fontanille 2015), while the voluminous output of phenomenologists is of particular usefulness to social semiotic research.

Alongside phenomenological inquiry and semiotic analysis, interpretive videography, an entrenched, yet experimental method amply utilized in ethnographic studies, allows us to appreciate how production aspects, such as video editing techniques and camera angles, impact directly on the signification of particular signs and cultural resources that are utilized in the stage-setting of the karaoke spectacle. It merits noticing that some of the research areas within the purview of videography already constitute common currency in social semiotics (cf. ledema 2008). Thus, the interaction of methods from all three strands allows us to furnish a more comprehensive outlook on how cultural identity is shaped through Corden's Karaoke spectacle.

Finally, in terms of sampling, each episode in the Carpool Karaoke series comprises one or more popular personas (mediators of cultural production), most eminently music artists, but also actors, and to a lesser extent politicians. The incidence of each type of hosted popular persona in the corpus that was utilized in this research is listed in Table 1. All episodes were sourced from the official show's YouTube channel (https://www.youtube.com/ user/TheLateLateShow). 
Table 1. Incidence of popular personas in different Carpool Karaoke sessions.

\begin{tabular}{|c|c|c|}
\hline & Name & Profession \\
\hline 1 & Adele & Singer \\
\hline 2 & Hamilton & Singer \\
\hline 3 & Carrie Underwood & Singer \\
\hline 4 & Chris Martin & Singer \\
\hline 5 & Demi Lovato and Chris Jonas & Singers \\
\hline 6 & Elton John & Singer \\
\hline 7 & Iggy Azalea & Singer \\
\hline 8 & Michelle Obama & Politician \\
\hline 9 & Gwen Stefani, George Clooney and Julia Roberts & Singer \\
\hline 10 & Jason Derulo & Singer \\
\hline 11 & Jennifer Hudson & Singer \\
\hline 12 & Jennifer Lopez & Singer \\
\hline 13 & Justin Bieber & Singer \\
\hline 14 & Mariah Carey & Singer \\
\hline 15 & One Way & Band \\
\hline 16 & Red Hot Chili Peppers & Band \\
\hline 17 & Rod Stewart & Singer \\
\hline 18 & Selena Gomez & Singer \\
\hline 19 & Sia & Singer \\
\hline 20 & Stevie Wonder & Singer \\
\hline
\end{tabular}

This study does not draw as much on each of the above episodes' particularities in terms of content or conversational turn-taking between Corden and guests, but rather seeks to outline the main signs and cultural resources that permeate invariably the episodes' stage-setting, as laid out in the following section.

\section{The dramaturgical scaffolding of Carpool Karaoke}

In this section, the stage-setting or dramaturgical scaffolding of Carpool Karaoke is deconstructed in terms of the signs, materials, processes, social actors, settings that comprise it as mobile locus of cultural production and cartographing medium of the urban.

Starting from the featured social actors, they consist of James Corden as the show's host and driver, plus one or more popular personas (mediators of cultural production), as described in Table 1.

The setting consists of the interior space of a sport utility vehicle, with a clear distribution of power as regards what seat is allocated to which social actor, based on relative popularity. Thus, Corden is always on the driver's seat, as (literally) host of the Late Late Show, but also, connotatively, as selector from a paradigmatic pool of cultural resources and diffuser of legitimately dominant popular trends.

Wherever more than one guests are involved, the co-driver's seat is customarily reserved for the most popular among them, whereas the back seats for the less popular (by comparison). For example, if an entire band's members are hosted in a Karaoke session, the co-driver's seat is usually occupied by the lead singer, whereas the back seats by the rest band members. This distribution of cultural production power qua popularity also corresponds to each guest's level of visibility in the context of a frontal panoramic camera angle that is usually adopted throughout the session, apparently with a view to enhancing the spectacle's realistic and not contrived nature (as might be afforded by multiple camera movements). 
The safety belt is always on, both as an integral aspect of the settings' materiality, as well as a sign of safety. The safety belt stands in a homological relationship with the driving theme that is reinforced by the presence of a legitimate cultural host. The host's "driving" stands metonymically for "safe" and "correct" cultural choices amidst an archipelagos of less coded, underground and peripheral sub-cultures that do not partake of the projected ethos. The sign of the safety belt, the stability of the camera angle, as the imposition of a uniform perspective or aspect-of-seeing on what is gazed at in the interior, selfreferential space of cultural production, and the selecting/diffusing role of the host as regards the choice of tracks constitute a homological chain. The chain also encompasses the physique of the host, that is clean-cut looks and teddy-bearish chubbiness, as well as the very onomatology of the cultural practice that envelopes the spectacle, that is Karaoke.

Karaoke may be read quite plausibly anagrammatically as "OK car," in the sense of "this is a safe car to drive." From a rhetorical point of view, the warrant for this claim is furnished self-referentially within the nexus of signs and cultural resources that make up each Karaoke session, most eminently the host's self-professed role as paradigmatic selector and diffuser of dominant popular trends. Self-referentiality in this instance is facilitated by the discursive particularities of musical composition that do not abide by the truthfulness criterion of propositional logic (Schutz 1996).

As regards the car-space per se, it constitutes a self-referential space (Nöth 2007) of absolute interiority as space for cultural production that is insulated from any outside interferences. Nothing exists outside of the insulated space of this "OK car" that is not warranted by the paradigmatically selective host.

The radio, or the staged selection of songs from the radio (as pre-selected songs that coincidentally match the profile of the hosted artists) is an integral cultural resource in the semiotic inventory of Corden's Karaoke. "The historical turning point between 'dwelling on the road' and 'dwelling in the car' can be located in a very specific technological development: the placing of a radio within the automobile" (Bull 2001, 188). It is part and parcel of the presumably unplanned, random ride through an urban landscape, rather than the meticulously premeditated taking over of the urban by staging a simulacrum of what constitutes a safe drive in the potentially alienating sea of not necessarily dominant (or popular) culture. The incidence of the radio as present through a makebelieve presencing tactic is also crucial in order to maintain a relationship with a non-controllable (by the host) environment where choices are made randomly and freely, without any inkling of manipulation that might mitigate the very essence of entertainment.

But what presents even greater interpretive challenges, in my view, is the actual role performed by the popular guests, as well as the function of the songs, coupled with the meaning of the singing mode in this multimodal spectacle (cf. Rossolatos 2015b). The latter will be tackled in the ensuing section. As will be shown in the following lines, the selection of songs and, concomitantly, artists takes place against the background of popularity, in terms of historical sales and often regardless of recency. Thus, diachronically popular artists such as Stevie Wonder, Elton John, Mariah Carey and Red Hot Chilli Peppers parade alongside more recently catapulted to stardom artists such as Adele and Justin Bieber.

The paradigmatic selectivity criterion with regard to songs as cultural resources affords to invest the show by transfer with an aura of classicism and authenticity, despite the frivolous mode of its actual execution. The mode of execution also includes the participants' 
gestures. Gestures (Monelle 1992; Tarasti 1997; Korte 2002) as dance moves constitute a key mode whereby the expressive potential of the selected songs is enhanced, constrained by the spatial arrangements of the car's interior. Thus, the selectivity criterion of diachronic popularity transpierces the syntagmatic deployment of each session as frivolous and ephemeral spectacle, thereby affording to invest the show with the hybrid axiology of normative entertainment.

As regards the actual proceedings of the spectacle, they encompass largely sing-along songs performed by James Corden along with the hosted artists who "happen" to be identical with the composers of the songs played on the OK car's radio. The re-enactment of the songs is interwoven with snappy dialogues between Corden and his guests that revolve thematically around the songs, also featuring recollections from the involved social actors' personal life narratives, interspersed with wider sociocultural implications.

The sung voice which is the primary semiotic mode in Corden's Karaoke sessions, conditions experience in its presencing, that is it constitutes the very mode of the experience's becoming present as such (Heidegger 2001). It does not establish a representational relationship with what is perceived, as is the case with visual spectacles, for example, that presuppose a distance between the actual object and how it is represented in perception. Rather, it constitutes an immersion in the pure presence of producing and consuming one's voice as one sings. The cultural implications of this pure presencing will be discussed in the ensuing sections.

In the context of Corden's staging strategy, music constitutes a necessary pre-condition for the utilization of resources and cultural signs whereby identity is negotiated situationally by the involved actors, as well as a key resource for cultural identity (DeNora 2005). These resources do not have a fixed meaning, but meaning potential (Griffith and Machin 2014) which is not exhausted in semiotic commutative relationships between the expression and content planes. In fact, the meaning potential of Corden's employment of music as repository of songs, as sung voice, as dance gestures and as communicative form that is not bound by propositional logic, is realized alongside pragmatic criteria.

Pragmatic criteria or more aptly, from a sociosemiotic point of view, the experiential meaning potential in terms of the resource's experiential, but also inter-personal metafunctions (Van Leeuwen 1999), pertain to how such resources afford to flesh out self-presencing and auto-affectivity as phenomenological conditionals of the media spectacle's self-referentially instituted mode of legitimacy, rather than as semantic correlations between signifiers/signifieds (Martin 2014). In this context, then, the experiential metafunction of the utilized resources assumes priority over the ideational one despite any different patterning in the metafunctions' ranking prior to the resources' appropriation by the karaoke spectacle. The appropriation of songs in the Karaoke spectacle does not resemanticize, but re-orders them by prioritizing the experiential and inter-personal metafunctions over the ideational one.

The final remark on the stage-setting of the Karaoke sessions concerns the role of the artists within the contours of this spectacle. As previously shown, the selected songs do not constitute by and large contemporary "hits," but classic popular songs. The primary function of the selected songs, in this setting, consists in transferring diachronic popularity to the show and by implication to the cultural host. The songs appear as having been selected not primarily as being representative of their producers, but as an appropriated hallmark of the show's staged diachronicity. The songs, once having been produced, are 
reduced to free-floating signifiers, not essentially linked to their producers, but as belonging to the paradigmatic pool of cultural resources that are available for selection from the cultural host. The songs are public property, expropriated from their producers who originally spawned them. The featured artists, thus, in this setting, do not perform their songs, but sing along their "own" songs, alongside the cultural host who is responsible for the songs' selection.

This peculiar-karaoke mode of employing songs as cultural resources in the presence of their composers calls for a different interpretive approach to what might be expected of music artifacts, that is an approach that depends in the very least on the formal compositional variables of songs (usually employed in tandem with a culturally oriented analytic; cf. Mirigliano 1995; Machin 2010), as against being vehicles for the enactment of the phenomenological conditions of self-presencing and auto-affectivity.

Although the situational role of the featured artists as producers of the employed musical signs is underplayed, they still constitute popular personas, Their popularity is utilized as a resource for projecting a prototypical consumer with whom the viewing audience may identify. The same holds for Corden himself, whose role in this respect is dual, both as cultural host, by virtue of being in a position to select and diffuse cultural artifacts, as well as prototypical consumer who sings to the radio-emitted songs alongside the rest prototypical consumers in the insulated space of the OK car. Let us now turn to an illustration of the importance of the singing mode in the constitution of cultural identity, against the background of salient stage-setting signs and cultural resources.

\section{The phenomenological constitution of cultural identity as temporal structure while hearing one's voice singing alongside others}

A customary point of argumentative departure in the extant literature in addressing the modes of formation of identity through music in urban settings is to contrast spatial with temporal conditions. Thus, "sound inhabits the subject just as the subject might be said to inhabit sound, whereas vision, in contrast to sound, represents distance, the singular, the objectifying. Therefore aural relational experience might well differ from a more visually orientated one" (Bull 2001, 189).

The crux of arguments regarding the primacy of temporally deploying signs over spatially deploying ones in construing a more proximate sense of self-presence, and hence of a directly lived experience, rather than a re-presentational one, concerns the notion of distance. DeNora (2005) assumes as a springboard for her aesthetic cultural analytic of the social functions of music Adorno's seminal writings on the sociology of music. Adorno's (1973) insightful analyses on the various ways whereby music mediates between agency and structure prioritized the existential function of music as lived experience, rather than as set of metaphors for investing various socially sanctioned pursuits. This is an essential facet of music's mission within contemporary urban landscapes that affords to shift focus from narrative aspects of cultural consumption and how these enable the metaphorical circumnavigation of the urban, towards more direct, immediate and selfpresent forms of cultural consumption as contemporaneous immersion. At the same time, the visio- (ocular-) centrism of cultural representations in a largely image-dominated cultural landscape presupposes a distance between what is gazed and the phenomena that are gazed at. This distance is effaced in the osmotic immersion of the auditory 
experience. "This sense of intimacy and immediateness, following Adorno, appears to be built into the very structure of the auditory medium itself" (Bull 2000, 32). Effacement of distance or crossing the distance between what is heard and what is meaningfully processed as being heard constitutes a relative competitive advantage of music versus image-driven spectacles. "Whereas vision is a distancing sense, hearing is one of alliance ... hearing ... does not keep the world at a distance, but admits it (Welsch 1997, 158)" (cited in Bull 2000, 118).

On the grounds of this crucial distinction between visiocentrism (or oculacentrism) and the direct immersion in lived musical experiences, DeNora (2005) addresses how music produces social effects. DeNora $(2005,151)$ focuses on how agency is produced through "aesthetic reflexive" practices in the context of self-induced preparation rituals whereby social actors prepare themselves for being motivated towards certain emotive states on specific social occasions (e.g. listening to musical piece $X$ in order to achieve exhilaration prior to attending a job interview). In this context, the social effects of music surface as an associative nexus between (i) personal narratives, (ii) conventional associations with musical genre or specific acts, (iii) music's formal properties and (iv) patterns of use (i.e. usage occasions). The interaction amongst these components yields patterns of urban existence.

The social effects of music have been amply researched from sociological (Hesmondhalgh 2008) and social psychological (Hargreaves and North 1999) points of view. Hargreaves and North (1999) listed an extensive set of music's effects, ranging from emotional expression and physical response to entertainment and communication. However, from a social phenomenological point of view we are concerned with pre-articulate modes of cultural identity formation. Vestiges of such approaches to the function of music may also be encountered in Adorno. "In Adorno's work the relationship between the auditory and states of 'we-ness' is intimate. Adorno perceives acoustic perception to be 'archaic' and pre-individualistic, embodying the memory and anticipation of a collective state" (Bull 2000, 123).

DeNora (2005) identifies the aforementioned capacity of music to function as a medium for directly lived and non-representational experiences of the urban with a "bodily tuning in." "To speak of this tuning in is to underline, however, that music was not 'operating on' participants like a stimulus or medium that 'made' them do things, but rather, it served as a medium to which participants oriented and could appropriate - albeit at a non-cognitive level" (DeNora 2005, 151). "Because music is itself a medium that unfolds through time, it can simultaneously mark, construct, and package time" (DeNora 2005, 156).

Let us now turn to Bull's (2000) study of the use of stereo equipment and music in urban settings in order to deepen our understanding of music's ability to transform urban existence into directly lived experience, rather than representational state. "The analysis of urban experience through the sense of vision has been the predominant one in urban and cultural studies" (Bull 2000, 116), at the expense of the auditory which has been undertheorised. In order to account for the unique mode whereby lived experiences of the urban are construed through music, Bull (2000) developed what he calls an auditory epistemology of urban experience. According to this auditory epistemology, social actors endow time with their own meaning as they transform their mundane journey into something more meaningful. This is conceived as a method of imposing an alternative routine 
over mundane linear time, whereby "the subjective appropriation of time is narrativized or transmuted into pleasure time" (Bull 2000, 66).

Although's DeNora's and Bull's argumentative lines are phenomenologically inclined (mainly due to including in their discussions Bergson's durée that is similar to Husserl's flux of inner time), they are not informed explicitly or consistently and at a sufficient length by specific phenomenological perspectives. As I will try to demonstrate, however, by recourse to Husserlian and Schutzian phenomenology, the aforementioned argument from distance is a weak one, insofar as distance is not effaced, but simply transformed from spatial to temporal distance. It is still a crucial difference insofar as a temporal distance is not as perceptible as spatial distance. However, this difference does not suffice for making a strong argument about the effacement of distance in the case of musical immersion versus visual representation, save for a milder argument for the ability to minimize rhetorically distances by dint of the absence of the condition of spatiality. As will be argued, instead of crossing (spatially) distances, we are confronted with re-tracing distances between signs that appeared originally in perception (the Husserlian thesis that does accord "originary presence" to the "initial" perception of a phenomenon, however contestable this thesis may be) and their retentional bringing forth. This point will be further elucidated by engaging in a dialogue between Husserl's arguments from the Phenomenology of Consciousness of Inner Time, Schutz's attempt to partially salvage the Husserlian phenomenology of inner time in his directly relevant for the analytic at hand adaptation of the original Husserlian theory to musical time and Derrida's criticisms of Husserl's vococentrism and philosophy of presence as deployed in Speech and Phenomena.

As discussed in the previous section, the unfolding of the Karaoke sessions in the insulated space of the moving vehicle (it is the vehicle that crosses, effaces, annihilates the spatial distance, not the social actors themselves, also marking an imaginary regression from real time to the imaginary time of entertainment) affords to minimize the importance of spatiality, while accentuating the primacy of musical temporality in bringing about the directly lived immersion of the involved actors in the staging of the spectacle. What is implied, though, in claiming alongside DeNora (2005) and Bull (2000), but also Schutz (1996) who shares this outlook, that listening to music, and even more so listening to oneself singing, constitutes a more directly lived experience (Ihde 2007) than an experience revolving around visuality? Moreover, and this is a more foundational question, why should a directly lived experience, uncontaminated by re-presentation, be valorized over a visual representation? This indirect axiological judgment as differential valorization is implied in DeNora's and Bull's arguments, albeit as a hidden premise. Let us unpack the axiological conditions of this empirical premise by recourse to Husserlian phenomenology.

Husserl, in line with the modernist enterprise, sought to furnish unshakable epistemic criteria for the production of knowledge. The employed heuristic in this philosophical inquiry concerns primarily the ability of a cogito (consciousness) to cognize truthfully the phenomena as they appear to itself. The most direct path as "test-drive" for diagnosing whether this cognizing mechanism is in fact fit for this purpose is to claim an ability to perceive phenomena in their original perception as they appear to the cogito, that is in full presence. The optimal pathway for gauging this ability is through the direct perception of one's voice insofar as listening to oneself speaking is uncontaminated by any external environmental cues that might distort the actual presential nature of phenomena. "Hearing oneself speak is experienced as an absolutely pure auto-affection, occurring in 
a self-proximity that would in fact be the absolute reduction of space in general. It is this purity that makes it fit for universality" (Derrida 1973, 79). The inner time of consciousness allows for registering one's voice while talking to oneself as such in full presence. The only way to verify the truthfulness of phenomena is by checking the intactness of consciousness as auto-affective mechanism. If the mechanism functions properly, then the cogito may proceed with more adventurous perceptions to the external world. The cogito's machinery belongs to the "transcendental subject" (in line with Kant) that conditions the empirical subject's ability not only to perceive, but, moreover, to synthesize sensedata into higher order concepts, to apprehend, to recollect, to imagine. Husserl (1980, 50 ), thus, inferred that affection is the locus of the "original" appearance of sense-data. Let it be noted that, as is the case with the vast majority of great philosophers, the concept of time was constantly reframed throughout his writings (cf. Kortooms 2002). Here, I am focusing on the Phenomenology of Consciousness of Internal Time as by itself it affords to dispel some popular misconceptions about the directly lived nature of the musical experience.

As regards the phenomenological fabric of a musical piece, we are not concerned with a stream of uncoordinated "nows" as discrete sense-data that appear in empirical consciousness, but with synthesized components by a transcendental consciousness that confers perceptual continuity to a data stream. The experience of a musical piece as gestalt consists minimally in actually present "nows" and largely in retentions (recollections of temporal points now past), carried forward to the present, and protentions, that is anticipations of nows to come that will effect a closure to the musical piece. Therefore, the experience of a musical piece is not unmediated or a directly lived experience in the self-transparency of now, but a series of retentions and protentions (Husserl 1980, 25) in a continuous stream that is safeguarded by the transcendental subject. As noted by Deely (2007), the intellect works always already on signs, rather than unmediated sensory data. Existence is a semiotization of experience, for it is the experience of signification (Grossberg 1982). The song is constituted as a song by virtue of the form of duration that is conferred to sense-data by the transcendental ego. Thus, listening to oneself singing and recognizing a song as being such and such, one might say, is a way whereby the transcendental consciousness may check the integrity of its inner operations against the background of empirical data. This is a fundamental tenet of Husserlian phenomenology (inasmuch as of Kantian epistemology), namely that a consciousness is always for phenomena inasmuch as phenomena do not exist without a consciousness. However, this musical experience is far from a direct one, insofar as it is made in the least of actual nows and largely of retained and protained signs.

Schutz (1996) commits the same flaw as DeNora and Bull by ascribing a more directly lived character to the musical experience in contrast to spatially conditioned experiences insofar as the musical experience is bereft of any spatial distance and hence assimilable to the "flux which is that of the stream of consciousness in inner time" (Schutz 1996, 258). However, it may be counter-argued, there is still a distance, albeit not of the same nature as spatial distance, but a temporal one. "Phenomena of short duration are nested within larger retentions and protentions" (Berger 1999, 238). For example, the last note in a 5-hour long opera as protained sign in inner consciousness, does not have the same distance from the beginning of the piece compared to a retained sign that was brought forward a couple of seconds as of the piece's beginning. Each musical 
second if sung by oneself may be experienced as full presence to oneself and auto-affection, however, it doesn't have meaning outside of the ideal duration of the track that is not fully present in inner time as one listens to one's voice. Therefore, Schutz's argument about the musical experience being assimilable to the flux of inner time is defeasible.

The time of music is certainly different from the time of movement in space, but by no means assimilable to the flux as succession of pure nows. Schutz's account is obfuscated in this respect due to the employment of the term "vivid experience" (corresponding to what was called earlier directly lived experience) in two contradictory senses. The first sense, as "actual vivid experience of a Now" (Schutz 1996, 261) lies closer to the directly lived experience, whereas the second sense, as "the vivid present encompasses everything that is actually lived through; it includes elements of the past retained or recollected in the Now and elements of the future entering the Now by way of protention or anticipation" (Schutz 1996, 257) corresponds to inner time as duration, but not as self-presence in the Now and, by implication, as listening to oneself singing in the Now. This contradiction in terms, though, may be attributed to the fact that this otherwise inspired piece was never completed, but published in draft status.

In order to lend further credence to the position that the argument from the self-presence of the voice as source of legitimacy for the cogito's universal validity (that underpins the more empirically oriented claims about the musical experience as directly lived versus spatially conditioned experiences) is a weak one, let us further consider some of the key arguments leveled by Derrida (1973) against Husserlian phono- (or voco-)centrism. "Considered from a purely phenomenological point of view, within the reduction, the process of speech has the originality of presenting itself already as pure phenomenon, as having already suspended the natural attitude and the existential thesis of the world" (Derrida $1973,78)$. "A now is a now only by means of self-affection, a movement in which retention is constitutive of the presence of the present itself" (Evans 1991, 112). Hearing oneself constitutes a simulation of the bracketing process whereby consciousness suspends its natural attitude (that is, beliefs, common places, etc.) while becoming aware of itself as pure consciousness. The suspension of the natural attitude constitutes a key moment in the phenomenological reduction process whereby cogito sinks into an endless involutionary path while becoming cognizant of its own ever-multiplying operations. The auto-affective relationship established by consciousness with itself in this moment of suspension "produces sameness within self-difference" (Derrida 1973, 82), the very sameness whose constant need for checking is tantamount to the maintenance of the transcendental ego's integrity. "As soon as one takes the movement of temporalization into account, as it is already analyzed in The Phenomenology of Internal Time-Consciousness, the concept of pure auto-affection must be employed" (Derrida 1973, 83). However, given that what is actually experienced, as a rule based on the preceding exposition, is an admixture of protentions and retentions, the purity of self-presence is unattainable. As Derrida argues, we are rather confronted always already with retracing, rather than nows. Therefore, "the self of the living present is primordially a trace" (Derrida 1973, 85), rather than a "now." This position mitigates both the presumed universality of the cogito by dint of its ability to perceive itself as auto-affective mechanism, as well as the musical experience as directly lived.

The cultural identity of the Carpool Karaoke participants, therefore, is not produced as full self-presence to oneself, as uncontaminated by retained and protained signs, but always already as an inauthentic (impure compared to the posited ideational purity of 
absolute self-presence) retracing. Husserl's attempt to salvage the modernist project by furnishing universally binding epistemic criteria turns out to be unattainable by arguing for self-presence (or as being assimilable to the pure flux of the inner consciousness, as argued by Schutz). If this auto-affective gimmick does not attain to confer authenticity (originality) to the show, then where are we left as regards its employment in Corden's karaoke? As will be shown in the next section, perhaps this was not the objective in the first place.

\section{The ironic reversal of "self-presence" as authenticity criterion and the post-modernist celebration of inauthenticity}

In continuation of the question that concluded the previous section, Corden appears to be Derridean throughout. The pre-representational lived experience of the now in the sung voice turns out to be an illusion. It is the effect of meaning (effet de sens) of the staging of self-presencing, facilitated by the insulated space of the OK car. The space of absolute interiority simulated by the insulated space of the OK car constitutes a theatrical enactment of the phenomenological reduction, that is the bracketing of the natural attitude. "Hearing oneself speak is not the inwardness of an inside that is closed in upon itself; phenomenological reduction is a scene, a theater stage" (Derrida 1973, 86). The insulation of the OK car from any exterior space and the opening up of the possibility of experiencing the production of culture authentically without interference from any exteriority, thus constitutes a self-referential ploy, a staged simulacrum that can only retrace retentional signs.

In fact, all participating social actors become present to themselves ironically by retracing what has already been played back in the "radio." They bring forth from memory what they anticipate will be the next verse, thus conflating the present and the anticipation of the future with the retracing of what has been. And Corden has proved over and over to be a master of irony, as, for example, in his comical re-enactment of famous movie scenes alongside the originally participating actors. This is precisely the post-modern twist that is conferred to the practice of legitimating criteria of authenticity, by engaging in a double movement whereby on the one hand Corden stages the necessary settings for claiming authenticity (i.e. insulation from exteriority and primacy of sung voice as absolute self-presencing, transparency and authenticity), whereas, at the same time, this selfprecensing as auto-affective listening to oneself is effected through a repetition of retentional sonic signs in tandem with what is played back through the "radio."

Corden's authentic stage-setting, ultimately, is geared towards an ironic celebration of the impossibility of authenticity as absolute self-presence and a constant reveling in inauthenticity, as re-appropriation and re-tracing, in short as repetitively kitsch (Binkley 2000). It is within such a phenomenological setting that both cultural identity is produced, inasmuch as the osmotic situational collective identity of the participating social actors whose voices intermingle within the insulated hyper-space of the OK car.

In conclusion, the popular entertainment form of the talk-show, and particularly Corden's novel gimmick of taking the talk-show to the city, or, rather, of bringing the urban to the insulated space of the moving talk-show, usurps and inverts cogito's universalism in two moves: first, by portraying the auto-affective relationship of the subject with its voice as a retracing of what is emitted through the radio, and, second, by subscribing to the impossibility of attaining authenticity as universally applicable criteria of legitimacy of 
cultural identity, save for the constant play among inauthentic modes-of-Being (in Heidegger's [2001] terms), conditioned by the free-floating signifiers of musical products. In this predicament, the control over the communication of the musical product shifts from sender/marketer to consumer, as "a process of partnership between the marketer and the consumer" (Firat and Dholakia 2006, 146).

At the same time, the OK car becomes the locus for the legitimate emergence of the social effects of music as cultural associations between personal life narrative fragments (e.g. memories of highschool relationships in association with the affect emanating from hearing oneself singing [Red Hot Chili Peppers episode]). "The quality and texture of affect is inextricably entwined with the values, projects, meanings, and ideologies for which they are enacted" (Berger 1999, 252). Being-with in the OK car as micro-social situational collective is, thus, tantamount to always already being-alongside-others in the everyday inauthenticity of Dasein (Heidegger's [2001] term for being as being [sein] there [da-]), that is always already caught up in the natural attitude nexus from which phenomenological reduction as uncontaminated self-presencing seeks to disentangle itself .

The talk-show institutes within the absolute interiority of its self-referential (Nöth 2007) simulacrum the ephemeral criteria that allow for legitimating every decision that concerns the urban and its inhabitants, at the expense of either universalist criteria premised on the cogito (Husserl) or of a univocal ground of Being (Heidegger). The popularity of the talkshow allows for legitimating everything, from dominant cultural signs (the invited artists) to political decisions (Michelle Obama's promise to educate all women of the world). The inner space of this cultural simulacrum, ultimately, functions as a protective shield against alienation in the vast sea of cultural indeterminacy.

\section{Conclusions}

The Carpool karaoke constitutes an innovative way of taking a popular entertainment show to the streets or, rather, of rendering the urban part of the self-enclosed space of the moving vehicle. The leveraging of the karaoke cultural practice by Corden was shown to be incumbent on claiming authenticity for the show by prioritizing certain signs and cultural resources over others. Most eminently, the preponderance of the voice and specifically the sung voice was found to be intimately tied up with the role performed by self-presence and inner temporality in the Husserlian modernist philosophical universalist project.

However, the appropriation of this self-presence by Corden is attained through an ironic reversal as retracing by the voice of what has already been played on the car's radio, but also as an effect of meaning afforded by the show's stage-setting strategy that features hearing oneself singing within a space of absolute interiority, totally insulated from any external interferences. In this context, the modernist quest for universally applicable criteria recedes against the dramaturgical, playfully inauthentic post-modern retracing of the sonic cultural resources.

\section{Acknowledgements}

I would like to thank the anonymous reviewers of Social Semiotics for their stimulating comments. 


\section{Disclosure statement}

No potential conflict of interest was reported by the author.

\section{Notes on contributor}

George Rossolatos is an academic researcher, marketing practitioner and the editor of the International Journal of Marketing Semiotics (Department of English, Kassel University, Germany). Major publications include the Handbook of Brand Semiotics (2015; ed. and coauthor), Semiotics of Popular Culture (2015), Brand Equity Planning with Structuralist Rhetorical ||Semiotics (2012, 2014), //rhetor.dixit//: Understanding Ad Texts' Rhetorical Structure for Differential Figurative Advantage (2013), Applying Structuralist Semiotics to Brand Image Research (2012), Interactive Advertising: Dynamic Communication in the Information Age (2002; ed. and coauthor), plus numerous articles in trade and academic journals. His research interests focus on new media and cultural studies, interpretivist consumer research, branding/advertising and span various disciplines such as rhetoric, semiotics, phenomenology, deconstruction, psychoanalysis and communication theory. Full CV downloadable from http://bit.ly/1cnUnVT.

\section{References}

Adorno, Theodor W. 1973. Philosophy of New Music. Minneapolis: University of Minnesota Press.

Berger, Harris M. 1999. Metal, Rock, and Jazz: Perception and the Phenomenology of Musical Experience. Delaware, OH: Wesleyan University Press.

Binkley, Sam. 2000. "Kitsch as a Repetitive System." Journal of Material Culture 5 (2): 131-152.

Bondi, Antonino, and Francesco La Mantia. 2015. "Phenomenology and Semiotics: Crossing Perspectives." Metodo: International Studies in Phenomenology and Philosophy 3 (1).

Brown, Barry, and Abigail Sellen. 2006. "Sharing and Listening to Music." In Consuming Music Together: Social and Collaborative Aspects of Music Consumption Technologies, edited by Kenton O'Hara and Barry Brown, 37-56. Amsterdam: Springer.

Bull, Michael. 2000. Sounding Out the City: Personal Stereos and the Management of Everyday Life. New York: Berg.

Bull, Michael. 2001. "Soundscapes of the Car: A Critical Ethnography of Automobile Habitation." In Car Cultures, edited by Daniel Miller, 185-202. New York: Berg.

Cohen, Sara. 1993. "Ethnography and Popular Music Studies." Popular Music 12 (2): 123-138.

Deely, John. 2007. Philosophy and Semiotics: A Story of Mutual Fecundation. Scranton: Scranton University Press.

DeNora, Tia. 2005. "Music and Social Experience." In The Blackwell Companion to the Sociology of Culture, edited by Mark D. Jacobs and Nancy Weiss Hanrahan, 147-159. Oxford: Blackwell.

DeNora, Tia. 2006. "Music and Emotion in Real Time." In Consuming Music Together: Social and Collaborative Aspects of Music Consumption Technologies, edited by Kenton O'Hara and Barry Brown, 19-34. Amsterdam: Springer.

Denzin, Norman K. 1997. Interpretive Ethnography: Ethnographic Practices for the 21st C. London: Sage.

Derrida, Jacques. 1973. Speech and Phenomena, and Other Essays on Husserl's Theory of Signs. Evanston: Northwestern University Press.

Evans, Jean Claude. 1991. Strategies of Deconstruction: Derrida and the Myth of the Voice. Minneapolis: University of Minnesota Press.

Ferguson, Harvie. 2006. Phenomenological Sociology: Insight and Experience in Modern Society. London: Sage.

Firat, Fuat A., and Nikhilesh Dholakia. 2006. "Theoretical and Philosophical Implications of Postmodern Debates: Some Challenges to Modern Marketing." Marketing Theory 6 (2): 123-162.

Fontanille, Jacques. 2015. "Formes de Vie: Des Jeux de Langage à la Phénoménologie des Cultures." Metodo: International Studies in Phenomenology and Philosophy 3 (1). 
Friesen, Norm, and Stacey Irwin. 2014. "Being Online Special Issue - Editors' Introduction." Phenomenology \& Practice 8 (1): 1-4.

Griffith, Frank, and David Machin. 2014. "Communicating the Ideas and Attitudes of spying in Film Music: A Social Semiotic Approach." Sign Systems Studies 42 (1): 72-97.

Grossberg, Lawrence. 1982. "Experience, Signification, and Reality: The Boundaries of Cultural semiotics." Semiotica 41 (1/4): 3-106.

Hargreaves, David J., and Adrian C. North. 1999. "The Functions of Music in Everyday Life: Redefining the Social in Music Psychology." Psychology of Music 27 (1): 71-83.

Heidegger, Martin. 1972. On Time \& Being. New York: Harper.

Heidegger, Martin. 1985. History of the Concept of Time: Prolegomena. Indianapolis: Indiana University Press.

Heidegger, Martin. 2001. Being \& Time. Oxford: Blackwell.

Hesmondhalgh, David. 2008. "Towards a Critical Understanding of Music, Emotion and Self-Identity." Consumption Markets \& Culture 11 (4): 329-343.

Hill, Annette. 2005. Reality TV: Audiences and Popular Factual Television. London: Routledge.

Husserl. E. 1980. Collected Works: Vol. IV On the Phenomenology of Consciousness of Internal Time. London: Kluwer.

ledema, Rick. 2008. "Analysing Film and Television: A Social Semiotic Account of Hospital, an Unhealthy Business." In Handbook of Visual Analysis, edited by Theo Van Leeuwen and Carey Jewitt, 183-206. London: Sage.

Ihde, Don. 2007. Listening and Voice: Phenomenologies of Sound. New York: SUNY.

Knoblauch, H. 2012. "Videography: Focused Ethnography and Video Analysis." In Video Analysis: Methodology and Methods Qualitative Audiovisual Data Analysis in Sociology, edited by $\mathrm{H}$. Knoblauch, B. Schnettler, J. Raab, and H. G. Soeffner, 69-84. Frankfurt: Peter Lang.

Korte, Melissa. 2002. "Leonard B. Meyer: On the Threshold of Musical Semiotics." Semiotica 142 (1/4): 447-460.

Kortooms, Toine. 2002. Phenomenology of Time: Edmund Husserl's Analysis of Time Consciousness. Amsterdam: Springer.

Lanigan, Richard L. 1984. Semiotic Phenomenology of Rhetoric. Boston, MA: University Press of America.

Lanigan, Richard L. 1997. "Communicology." In Encyclopedia of Phenomenology, edited by Lester Embree, 104-110. Boston, MA: Kluwer.

Lindseth, Anders, and Astrid Norberg. 2004. "A Phenomenological Hermeneutical Method for Researching Lived Experience." Scandinavian Journal of Caring Sciences 18: 145-153.

Machin, David. 2010. Analyzing Popular Music: Image, Music, Text. London: Sage.

Man Kong Lum, Casey. 2005. "The Karaoke Dilemma: On the Interaction Between Collectivism and Individualism in the Karaoke Space." In Karaoke Around the World: Global Technology, Local Singing, edited by Toru Mitsui and Shuhei Hosokawa, 161-172. London: Routledge.

Martin, Jodie L. 2014. "Semiotic Resources of Music Notation: Towards a Multimodal Analysis of Musical Notation in Student Texts." Semiotica 200: 185-201.

Mirigliano, Rosario. 1995. "The Sign and Music: A Reflection on the Theoretical Bases of Musical Semiotics." In Musical Signification: Essays in the Semiotic Theory and Analysis of Music, edited by Eero Tarasti, 43-62. Berlin: Mouton.

Monelle, Raymond. 1992. Linguistics and Semiotics in Music. Tokyo: Harwood.

Mumford, Lewis. 2004. "What Is a City?" In The City Cultures Reader, edited by Malcolm Miles, Tim Hall, and lain Borden, 28-32. London: Routledge.

Nöth, Winfried. 2007. "Self-reference in the Media: The Semiotic Framework." In Self-Reference in the Media, edited by Winfried Nöth and Nina Boshara, 3-30. Berlin: Mouton.

Pink, Sarah. 2006. Doing Visual Ethnography. London: Sage.

Rossolatos, George. 2015a. "The Brand Imaginarium, or on the Iconic Constitution of Brand Image." In Handbook of Brand Semiotics, edited by George Rossolatos, 390-457. Kassel: Kassel University Press.

Rossolatos, George. 2015b. "Taking the 'Multimodal Turn' in Interpreting Consumption Experiences." Consumption, Markets \& Culture 18 (5): 427-446. 
Schutz, Alfred. 1996. Collected Papers Vol. IV, Appendix: Fragments Toward a Phenomenology of Music. Amsterdam: Kluwer.

Shaw, Spencer. 2000. Film Consciousness: From Phenomenology to Deleuze. London: McFarland.

Sheller, Mimi, and John Urry. 2004. "The City and the Car." In The City Cultures Reader, edited by Malcolm Miles, Tim Hall, and lain Borden, 202-219. London: Routledge.

Sobchack, Vivian. 1992. The Address of the Eye: A Phenomenology of Film Experience. Princeton, NJ: Princeton University Press.

Tarasti, Eero. 1987. Existential Semiotics. Berlin: Mouton.

Tarasti, Eero. 1997. "The Emancipation of the Sign. On the Corporeal and Gestural Meanings in Music." Applied Semiotics Journal 4 (Special Issue on Musical Semiotics): 180-190.

Vaitkus, Steven. 1990. How Is Society Possible? Intersubjectivity and the Fiduciary Attitude as Problems of the Social Group in Mead, Gurwitsch, and Schutz. Amsterdam: Kluwer.

Van Leeuwen, Theo. 1991. "The Sociosemiotics of Easy Listening Music." Social Semiotics 1 (1): 67-80. Van Leeuwen, Theo. 1999. Speech, Music, Sound. London: Macmillan. 